\title{
Chronic proximal aortic dissection presenting as tamponade after 16 years
}

\author{
A G FRASER, S PASSANI, * M W JAYWARD $†$ \\ From the Departments of Cardiology, Cardiac Surgery, ${ }^{\star}$ and Radiology, $\dagger$ University Hospital of Wales, \\ Cardiff
}

SUMMARY A patient presented with tamponade and haemopericardium 16 years after experiencing sudden severe chest pain associated with enlargement of the proximal aorta. Investigations revealed a proximal aortic dissection (DeBakey type II) with extensive laminar and partially calcified thrombus within its false lumen and a large pericardial effusion, which together resulted in a cardiothoracic ratio of $100 \%$. Long term survival after medical treatment of proximal aortic dissection, with such late progression to tamponade, has not been reported before.

The terminal event in more than two thirds of patients who die soon after proximal dissection of the aorta is intrapericardial rupture progressing rapidly to massive haemopericardium and tamponade. ${ }^{1}$ Even when it does not cause a haemopericardium, acute proximal aortic dissection carries a poor prognosis. ${ }^{2}$ In a review of 425 patients none of those treated medically survived for more than nine years. ${ }^{1}$ When patients do survive with chronic aortic dissection, symptoms are most frequently those of congestive heart failure rather than tamponade.

We report a patient in whom tamponade developed 16 years after the initial aortic dissection.

\section{Case report}

A 56 year old woman was admitted on 1 October 1985 complaining of breathlessness which had increased progressively over three weeks. She could walk for only 10 yards; she was breathless at rest and dizzy when standing. She also reported epigastric discomfort and anorexia.

She had been treated for hypertension since the age of 27, after having nephritis when she was seven and pyelitis when she was 21 . Blood pressure control was poor; in January 1968 it was recorded at 190/130 $\mathrm{mm} \mathrm{Hg}$.

In May 1969 when she was 40 she experienced abrupt "excruciating" central chest pain while standing and pulling heavy curtains. This did not

Requests for reprints to Dr A G Fraser, Department of Cardiology, University Hospital of Wales, Heath Park, Cardiff CF4 4XW. radiate and was not pleuritic. It settled after an hour, but later recurred for one more hour. In hospital an initial diagnosis of acute myocardial infarction was not confirmed by any electrocardiographic abnormality nor an increase in cardiac enzymes. One month later persistent chest discomfort and breathlessness developed. Blood pressure was 140/90 $\mathrm{mm} \mathrm{Hg}$. Serum haemoglobin was $7.5 \mathrm{~g} / \mathrm{dl}$ and the erythrocyte sedimentation rate was $100 \mathrm{~mm}$ in the first hour. The chest radiograph showed considerable distension of the ascending aorta and arch (fig 1a). A cardiologist suggested that she had a dissection of the aorta but further investigations were not performed.

In 1975 at the age of 46 she reported a two week history of feeling faint and breathless, with sharp chest pains. The chest radiograph (fig $1 \mathrm{~b}$ ) showed an increase in the size of the cardiac silhouette with an abnormal right heart border. Her symptoms were attributed to postural hypotension, and her treatment was changed from methyldopa to oxprenolol. In 1978 she was referred for cardiological investigations because of tiredness, faintness, and palpitation; the cardiothoracic ratio was further increased. Aortography in March 1979 demonstrated a proximal dissection of the aorta (DeBakey type II) with the origin of the false lumen arising a few centimetres above the junction between the right and non-coronary sinuses of Valsalva (fig 2). The cavity of the false lumen was smooth and its neck was well circumscribed; because it was much smaller than the opacity on the chest radiograph the false lumen was thought to contain an extensive 


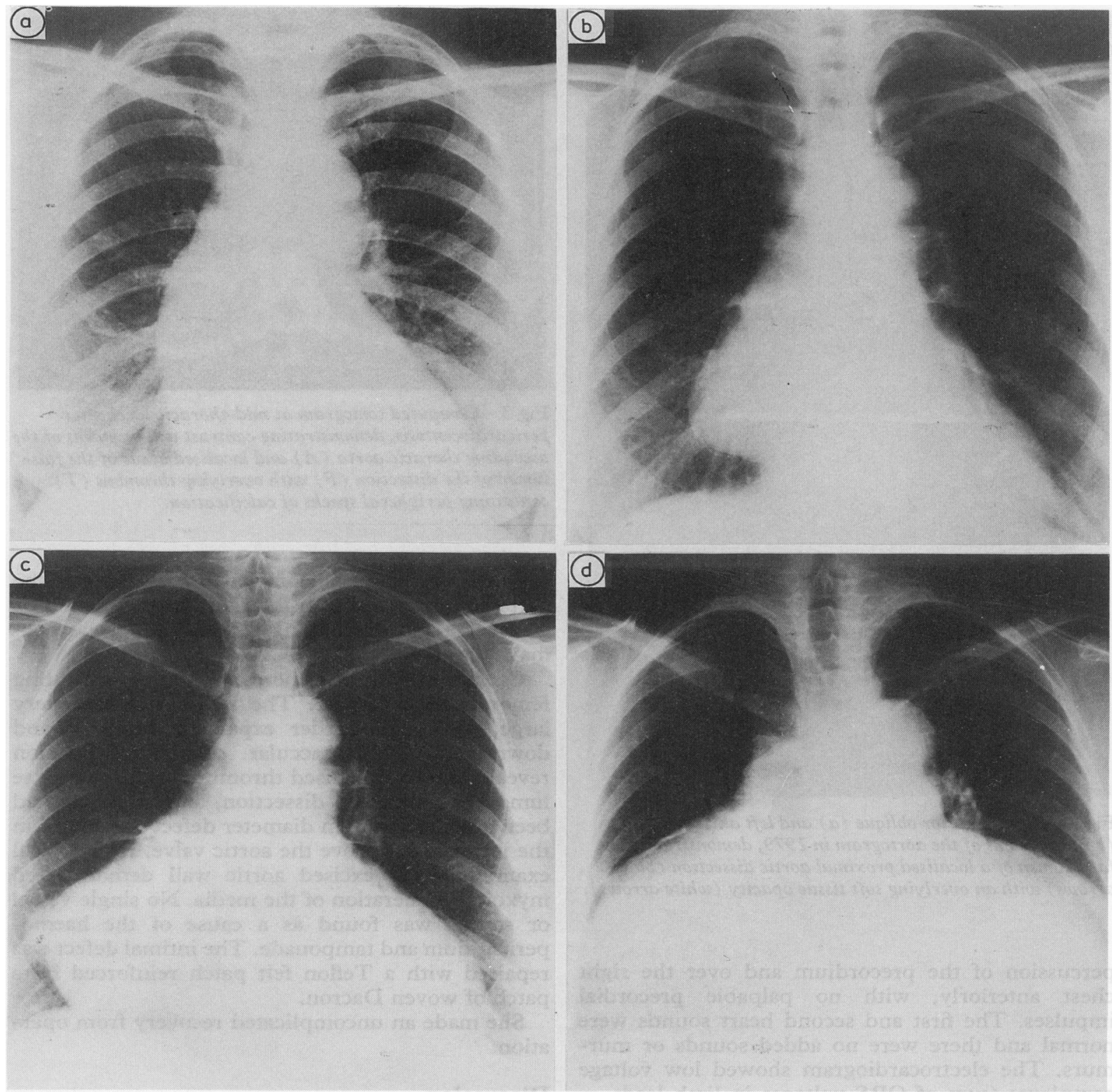

Fig 1 Serial posteroanterior chest radiographs in a patient with chronic dissection of the proximal aorta. (a) 1969; (b) 1975; (c) 1979, unchanged during follow up to 1982; (d) 1985.

amount of thrombus. There was no aortic regurgitation. She was referred for elective operation and subsequently admitted, but the operation was postponed because she was symptom free and there had been no change in the radiographic appearances during a 6 month period that she was on the waiting list: She was reviewed as an outpatient until 1982 (see chest radiograph fig 1c) but was then lost to follow up.

On this most recent admission she was unwell, breathless at rest, and centrally cyanosed. She had a sinus tachycardia with poor volume arterial pulses and paradox of $25 \mathrm{~mm} \mathrm{Hg}$. The jugular venous pressure was grossly elevated. There was dullness on 


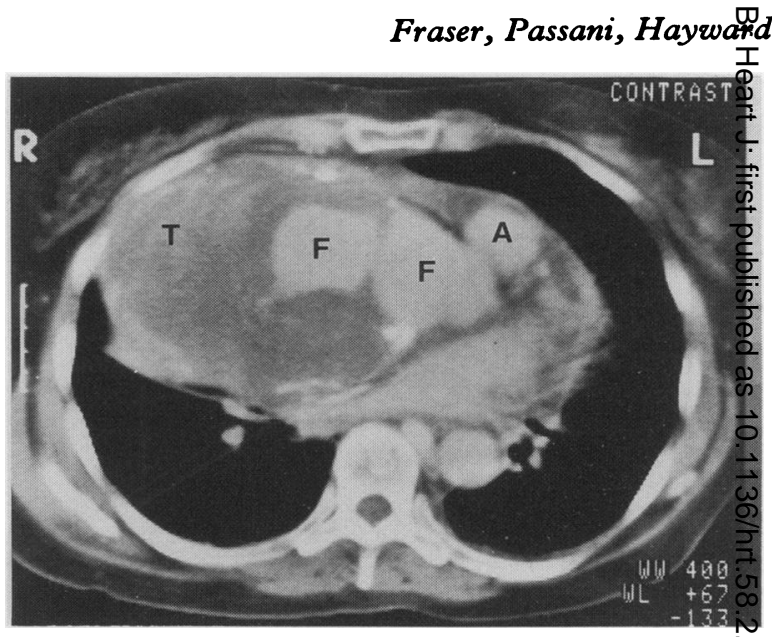

Fig 3 Computed tomogram at mid-thoracic level after $\vec{\sigma}$ pericardiocentesis, demonstrating contrast enhancement of the ascending thoracic aorta $(A)$ and localised areas of the fals lumen of the dissection $(F)$ with overlying thrombus $(T)-$ containing peripheral specks of calcification.

ing many areas of calcification that enveloped the aorta and extended into the right hemithorax. The transverse and descending thoracic aorta was not mal.

Cardiac surgery was performed after institutiò femorofemoral bypass. The aortic root was vemy large; its lateral border expanded outwards and downwards as a saccular dilatation. Incision revealed much organised thrombus within the false lumen of a localised dissection, and after this hăd been evacuated a $2 \mathrm{~cm}$ diameter defect was found the intima $4 \mathrm{~cm}$ above the aortic valve. Histological examination of excised aortic wall demonstrat $\bar{\sigma} d$ myxoid degeneration of the media. No single vesșel or source was found as a cause of the haemipericardium and tamponade. The intimal defect was repaired with a Teflon felt patch reinforced byôa patch of woven Dacron.

She made an uncomplicated recovery from ope ation.

\section{Discussion}

This patient is unusual because she survived for $\frac{10}{6}$ years after a proximal aortic dissection which weas treated medically and because she then presented with tamponade.

The circumstantial evidence indicates that $s \bar{h}_{\mathrm{e}}$ suffered a dissection in 1969, on a background :of hypertension and during physical exertion, which Ts an associated factor in some acute dissection Thereafter there was a gradual increase in the cardiothoracic ratio, presumably as thrombus consmall false lumen and extensive thrombus contain- 
tinued to be laid down within the false lumen. The episode in 1975 suggests an acute exacerbation of this process, and subsequent treatment with a $\beta$ adrenoceptor antagonist may have slowed the rate of progression. ${ }^{4}$ The most likely cause of the tamponade is that blood gradually leaked into the pericardial cavity from the dissecting haematoma.

About a quarter of patients with aortic dissection present with symptoms that have lasted for more than one month, ${ }^{35}$ and survival with chronic dissection of the descending or abdominal aorta is well documented. There have, however, been very few reports of dissection of the ascending aorta with survival beyond a few months. Africa et al reported a patient who had a dissection for four years. ${ }^{6}$ Taber and Lam described a patient with chronic dissection of the descending thoracic aorta (DeBakey type III) who presented with pericardial symptoms after five years. ${ }^{7}$ Tamponade has been reported from the late retrograde extension of a type III dissecting aneurysm ${ }^{8}$ and from retrograde dissection of an abdominal aortic aneurysm, ${ }^{9}$ but we have been unable to find any reports of such late development of tamponade after a chronic type II aortic dissection. In some cases it may be difficult to distinguish between dissection secondary to an atherosclerotic aneurysm and saccular dilatation at the site of a chronic dissection, but in the present case there can be little doubt that the primary event was a localised dissection.

Although thrombus may prevent rupture by acting as a buttress around the aorta, ${ }^{10}$ even when proximal dissection is not diagnosed until some weeks after the acute event, operation is indicated because it is usually associated with a good prognosis in these circumstances, ${ }^{411}$ whereas without operation haemopericardium causes death in $25 \%$ of patients. ${ }^{1}$ With earlier diagnosis, operation is even more important because tamponade is the fatal event in $80 \%$ of patients who have a proximal aortic dissection treated medically. ${ }^{12}$

Dissection of the aorta is the second most common cause of haemopericardium, ${ }^{13}$ and chronic dis- section should be considered as a cause even when there is no recent history to suggest dissection.

\section{References}

1 Hirst AE, Johns VJ, Kime SW. Dissecting aneurysm of the aorta: a review of 505 cases. Medicine (Baltimore) 1958;37:217-79.

2 Anagnostopoulos CE, Prabhakar MJS, Kittle CF. Aortic dissections and dissecting aneurysms. Am J Cardiol 1972;30:263-73.

3 Slater EE, DeSanctis RW. The clinical recognition of dissecting aortic aneurysm. Am J Med 1976;60: 625-33.

4 Wheat MW. Acute dissecting aneurysms of the aorta: diagnosis and treatment-1979. Am Heart J 1980;99:373-87.

5 Dalen JE, Pape LA, Cohn LH, Koster JK, Collins JJ. Dissection of the aorta: pathogenesis, diagnosis and treatment. Prog Cardiovasc Dis 1980;23:237-45.

6 Africa G, Bongiovanni G, Bertoli G. Su di un caso di aneurisma dissecante cronico "guarito" con formazione di "aorta a doppia canna". Pathologica 1981;73:105-9.

7 Taber RE, Lam CR. Diagnosis and treatment of chronic dissecting aneurysm of the thoracic aorta. $J$ Thorac Cardiovasc Surg 1963;45:186-97.

8 Verdant A, Cossette R, Dontigny L, Mercier C, Page A, Page P. Acute dissection of the descending thoracic aorta: repair in an unusual case. Can J Surg 1984;27:390-1.

9 Snow N. Hemopericardium from retrograde dissection of an abdominal aortic aneurysm. Am Surg 1980;46:589-92.

10 Dinsmore RE, Willerson JT, Buckley MJ. Dissecting aneurysm of the aorta. Aortographic features affecting prognosis. Radiology 1972;105:567-72.

11 Miller DC, Stinson EB, Oyer PE, et al. Operative treatment of aortic dissection. Experience with 125 patients over a sixteen-year period. $J$ Thorac Cardiovasc Surg 1979;78:365-82.

12 Appelbaum A, Karp RB, Kirklin JW. Ascending vs descending aortic dissections. Ann Surg 1976;183: 296-300.

13 Barbour BH, Hirst AE, Johns VJ. Nontraumatic hemopericardium. Analysis of 105 cases. Am J Cardiol 1961;7:102-8. 